\title{
Evaluation of Remotely Sensed Evapotranspiration Over the CEOP EOP-1 Reference Sites
}

\author{
H. SU, E.F. WOOD \\ Department of Civil and Environmental Engineering, Princeton University, Princeton, NJ 08544, USA
}

M.F. MCCABE

Los Alamos National Laboratory, PO Box 1663, MS-D436, Los Alamos, NM 87545, USA

and

Z. SU

International Institute for Geo-Information Science and Earth Observation (ITC), Hengelosestraat 99, P.O. Box 6, 7500 AA Enschede, The Netherlands

(Manuscript received 18 February 2006, in final form 26 October 2006)

\begin{abstract}
In this paper, the Coordinated Enhanced Observing Period (CEOP) data during an Enhanced Observing Period (EOP-1) is used to assess the Surface Energy Balance System (SEBS) model. The purpose of this study is to evaluate the adaptability of SEBS to different climatic zones and land cover classifications at two different scales. The SEBS model was examined at the field (tower) scale based primarily on in-situ observations from CEOP sites. To examine a broader scale application, remotely sensed land surface temperature (LST) from the MODIS sensor and surface meteorology from the Global Land Data Assimilation System (GLDAS) were used for the required forcing datasets. Comparisons at tower scale show that the model predictions of the energy fluxes agree reasonably well with the observations. The root mean square error (RMSE) of the ET prediction based on MODIS Land Surface Temperature (LST) plus CEOP meteorological observations is about $61 \mathrm{~W} \mathrm{~m}^{-2}$ at a grassland site (Cabauw) and a needle leaf forest site (BERMS). The RMSE of ET predication at a corn site (Bondville) is $96 \mathrm{~W} \mathrm{~m}^{-2}$ and the corresponding percentage error is $28.9 \%$. When GLDAS forcing was used instead of the CEOP tower observations, the RMSEs of ET prediction at Cabauw, BERMS and Bondville are increased to 82, 84 and $140 \mathrm{~W} \mathrm{~m}^{-2}$ respectively. The negative bias of surface downward radiative forcing from GLDAS contributed much to the larger deviation of the ET prediction when compared to tower based values. The innovative aspects of our study in this paper are: a) No similar work on evaluating remote sensing based ET model under a diverse climate and land cover condition has been done before; b) ET modeling was assessed in different scales ranging from site scale to GLDAS grid cell; c) The framework of estimating the spatial distribution of ET combining satellite data and available ground meteorology is tested.
\end{abstract}

Corresponding author: Hongbo $\mathrm{Su}$, Department of Civil and Environmental Engineering, Princeton University, Princeton, NJ 08544, USA.

E-mail: hongbosu@princeton.edu

(C) 2007, Meteorological Society of Japan

\section{Introduction}

Evapotranspiration $(E T)$ is the combination of water evaporated from the surface and transpired by plants and has been the focus of 
intensive research for many decades (e.g., Penman 1948; Priestley and Taylor 1972; Monteith 1981). ET is an important process which links the different components of the energy balance and water cycle for the atmospheric and land surface, and much research is focused on quantifying this process (Famiglietti and Wood 1991; Braun et al. 2001). Conventional measurement techniques such as the Bowen ratio and eddy covariance approaches provide relatively accurate means to estimate components of energy balance, but are essentially point scale predictions. Such local scale measurements are inadequate in studying the land surface energy balance at regional or global scales, due in part to the spatial heterogeneity of the land surface parameters and the dynamic nature of the evaporative process (Famiglietti and Wood 1995; Hu and Islam 1998).

Remote sensing techniques can make it possible to estimate the surface energy components at a regional to global scale (Bastiaanssen et al. 1998; Kustas and Norman 1996; Su and Menenti 1999). There remain however, significant issues related to the appropriate validation of regionally or globally distributed model predictions, particularly as the scaling behavior of the hydrological fluxes require careful consideration (Wood 1995; McCabe et al. 2005) and the choice of representative validation sites is critical for thorough model evaluation (Adolphs 1999; Plana 2002).

The Surface Energy Balance System (SEBS) proposed by $\mathrm{Su}(2002)$ is a model which integrates satellite data and available surface meteorological information to estimate atmospheric turbulent fluxes and the evaporative fraction at the land surface. It has been evaluated and applied from the tower to regional scale ( $\mathrm{Su}$ 2002; Jia et al. 2003; Su et al. 2005) and found to accurately reproduce the measured fluxes. However to date, validation studies have been predominantly undertaken as local scale evaluations over specific hydroclimatic and land surface conditions.

Both observations and theoretical simulation show that the climate condition and vegetation cover type have a major control on surface energy flux patterns (Lafleur and Rouse 1995; Bridgham et al. 1999; MacKay et al. 2002). At the same time, changes in these energy flux patterns could have a complex effect on the cli- mate variability (Delworth and Manabe 1993) and may "amplify or reduce the effects of potential climatic change" (Eugster et al. 2000). Undoubtedly, improved estimation of ET at larger scales is essential to improve our understanding of the global climate and its variability, both in the spatial and temporal domain (Miller et al. 1995).

SEBS requires evaluation against diverse data to assess its potential for routine global scale evapotranspiration estimation. Specifically, the SEBS model needs to be evaluated in a variety of climate zones and land covers, thereby assessing the adaptability of the SEBS model to climate and land cover variability. To fulfill this goal, a validation dataset that satisfies these criteria is required. The Coordinated Enhanced Observing Period (CEOP) forms an element of the World Climate Research Program (WCRP) (Koike 2002). Initiated as part of the Global Energy and Water Cycle Experiment (GEWEX), the CEOP dataset is ideal for the requirements of the SEBS validation, providing continuous high quality in-situ measurements at various locations across the globe.

In our study, eight CEOP stations are used to assess the SEBS model, specifically encompassing a variety of hydroclimatic conditions. Since in-situ observations of the surface broadband emissivity, leaf area index $(L A I)$ and vegetation fraction $(V F)$ are not routinely available from the CEOP dataset, these land surface parameters are derived from MODIS land products. An inter-comparison of energy fluxes from SEBS predictions and in-situ eddy correlation based observations are examined at daily and 10-day scale for each station.

Spatially representative in-situ data is often only available at a limited number of sites. Operational remotely sensed data and meteorological data from the Global Land Data Assimilation System (GLDAS) have been incorporated into the SEBS model to derive the evapotranspiration, to alleviate model dependence on ground measurements. In the satellite based analysis, MODIS LST is coupled with meteorology from CEOP and GLDAS (Rodell et al. 2004) to formulate two different forcing datasets for SEBS, offering a thorough examination of the impact on $E T$ prediction from varying scales of meteorological forcing data. 
Table 1. SEBS model data requirements (The observations in italic are used for validation purposes).

\begin{tabular}{|c|c|c|}
\hline Data Type & Variables & Possible Sources \\
\hline \multirow{4}{*}{ Surface Meteorology } & Air temperature & \multirow{4}{*}{$\begin{array}{l}\text { In situ Observation, or Land Data Assimilation } \\
\text { Database }\end{array}$} \\
\hline & Pressure & \\
\hline & Wind & \\
\hline & Humidity & \\
\hline \multirow{4}{*}{ Radiative Energy Flux } & Incident Shortwave Radiation & \multirow{4}{*}{ In situ Observation, or Satellite Retrieval } \\
\hline & Outgoing Shortwave Radiation & \\
\hline & Downward Longwave Radiation & \\
\hline & Outgoing Longwave Radiation & \\
\hline \multirow{7}{*}{ Land Surface Variables } & Land Surface Temperature & \multirow{7}{*}{ In situ Observation, or Satellite Retrieval } \\
\hline & Emissivity & \\
\hline & Albedo & \\
\hline & Vegetation Height & \\
\hline & Vegetation Fraction & \\
\hline & Leaf Area Index & \\
\hline & Vegetation Type & \\
\hline \multirow{4}{*}{ Surface Energy Flux } & Ground Heat Flux & \multirow{4}{*}{ In situ Observation } \\
\hline & Sensible Heat Flux & \\
\hline & Latent Heat Flux & \\
\hline & Net Radiation & \\
\hline
\end{tabular}

\section{Model description}

The Surface Energy Balance System (SEBS) model was proposed by $\mathrm{Su}$ (2002) to estimate the surface energy balance and evaporative fraction using remotely sensed data in combination with surface meteorological data. Currently, a MODIS based terrestrial ET algorithm is under development mainly using the SEBS model. The required data variables by SEBS are listed in Table 1.

The net radiation, ground heat flux and evaporative fraction are estimated in separate modules in SEBS, although the different modules share some common variables, such as the vegetation parameters. A brief overview of the methods used to estimate the net radiation, soil heat flux and the partitioning of available energy into sensible and latent heat fluxes in SEBS is presented below, but the reader is re- ferred to ( $\mathrm{Su} 2002)$ for a more thorough explanation.

Net radiation is estimated using radiative energy balance at the land surface:

$$
R_{n}=(1-\alpha) R_{s w d}+\varepsilon R_{l w d}-\varepsilon \sigma T_{s}^{4},
$$

where $\alpha$ is the broadband albedo in the visible and near infrared band, $\varepsilon$ is the broadband emissivity in the thermal infrared band, $R_{s w d}$ is the incident solar radiation, $R_{l w d}$ is the downward longwave radiation, $T_{s}$ is the surface temperature and $\sigma$ is the Stephan-Boltzman constant.

In satellite based applications or at large regional scales, ground heat flux measurements are generally unavailable. To account for this lack, an empirical parameterization of the ground heat flux based on net radiation and the vegetation fraction is used to estimate the 
total ground heat flux for the pixel. If the ground heat flux ratio is defined as:

$$
\Gamma=G_{0} / R_{n}
$$

Then, the ground heat flux can be parameterized following (Monteith 1973) and (Kustas and Daughtry 1990):

$$
G_{0}=R_{n} \cdot\left(\Gamma_{v} f_{v}+\Gamma_{s}\left(1-f_{v}\right)\right)
$$

where $\Gamma_{v}$ and $\Gamma_{s}$ are the ground heat flux ratios for full vegetation covered area and for bare soil respectively, $f_{v}$ is the vegetation fraction. It should be noted that $\Gamma_{s}$ and $\Gamma_{v}$ are dependent on vegetation types and climate conditions.

The partitioning of latent heat $(L E)$ and sensible heat $(H)$ from the available energy is achieved in part by solving the following set of equations which are based on the similarity theory of the atmospheric surface layer (Brutsaert 1982, 1999):

$$
\begin{aligned}
& u=\frac{u_{*}}{k}\left[\ln \left(\frac{z-d_{0}}{z_{0 m}}\right)-\Psi_{m}\left(\frac{z-d_{0}}{L}\right)\right. \\
& \left.+\Psi_{m}\left(\frac{z_{0 m}}{L}\right)\right] \\
& \theta_{0}-\theta_{a}=\frac{H}{k u_{*} \rho C_{p}}\left[\ln \left(\frac{z-d_{0}}{z_{0 h}}\right)\right. \\
& \left.-\Psi_{h}\left(\frac{z-d_{0}}{L}\right)+\Psi_{h}\left(\frac{z_{0 h}}{L}\right)\right], \\
& L=-\frac{\rho C_{p} u_{*}^{3} \theta_{v}}{k g H}
\end{aligned}
$$

where $u$ is the wind speed, $u_{*}$ is the friction velocity, $\rho$ is the air density, $C_{p}$ is the specific heat of air at constant pressure, $k$ is the von Karman's constant, $d_{0}$ is the zero plane displacement, $z$ is the height above the surface, $z_{0 m}$ and $z_{0 h}$ are the roughness height ${ }^{1}$ for momentum and heat transfer respectively, $\theta_{0}$ and $\theta_{a}$ are the potential temperatures at surface and at height $z$ respectively, $\Psi_{h}$ and $\Psi_{m}$ are the stability correction functions for sensible heat and momentum transfer respectively, $L$ is the Obukhov length, $g$ is the acceleration due to

1 The initial values of the roughness lengths and displacement height are from a look-up table which is adapted from land surface models (http://ldas.gsfc.nasa.gov/LDAS8th/MAPPED.VEG/ web.veg.table.html). Then the roughness lengths for momentum and heat transfer are adjusted during the iterative solution of Eq. (4). gravity and $\theta_{v}$ is the virtual temperature near the surface.

\section{Data and site description}

In attempting the inter-comparison of results, a number of different data sets were collated based on different sources of operational meteorology determined either from the CEOP or from the GLDAS data. These forcing datasets are compiled and listed in Table 2, with both the data sources and their scales described. The surface meteorological variables include wind speed, humidity, pressure, air temperature, downward shortwave and longwave radiation. The meteorological data in Dataset I was hourly observed from CEOP sites, while the Forcing Dataset II (CEOP+MODIS) and III (GLDAS+MODIS) are daily instantaneous, to match with the overpass time of MODIS. The three different forcing datasets represent a variety of scales, ranging in the spatial domain from the tower scale to the MODIS $1 \mathrm{~km}$ and from instantaneous to hourly in the time domain. Basically, the error in the model predictions is composed of two parts. One is caused by the scale disparity of forcing data; the other is due to the scale dependence of the model itself. We agree that it is hard to separately isolate the scale dependence of the model predictions from the influences of the model and the measurements. It is challenging in the study of $E T$, since spatial representative of the measurement of $E T$ in natural conditions ranges from tens of meters to kilometers, depending on both the heterogeneity of the site characteristics and the limitation of the instruments. To separate the influences from the model analysis and measurements, one possible method may be the numerical simulation, where the heterogeneity of the forcing is more controllable. In our current study, the "impact on ET prediction" is actually the comprehensive influences from the combination of model analysis and measurements.

The hourly in-situ measurements of the surface energy fluxes from CEOP sites are employed to compare with the model predictions from Forcing Dataset I. To compare with the surface heat flux estimation from the other two Forcing Datasets, the measurements of the surface energy fluxes from CEOP sites are interpolated linearly, just like the processing of the 
Table 2. Forcing datasets for SEBS.

\begin{tabular}{|c|c|c|c|c|}
\hline & Data Source & Variables & Spatial Resolution & Temporal Resolution \\
\hline \multirow{4}{*}{ Forcing Dataset I } & CEOP & Surface meteorology & Tower scale & Hourly \\
\hline & \multirow{3}{*}{ MODIS } & Emissivity & $1 \mathrm{~km}$ & Instantaneous \\
\hline & & LAI & $1 \mathrm{~km}$ & 8-day \\
\hline & & Land Cover & $1 \mathrm{~km}$ & Yearly \\
\hline \multirow{5}{*}{ Forcing Dataset II } & CEOP & Surface meteorology & Tower scale & Instantaneous, interpolated \\
\hline & \multirow{4}{*}{ MODIS } & LST/Emissivity & $1 \mathrm{~km}$ & Instantaneous \\
\hline & & LAI & $1 \mathrm{~km}$ & 8-day \\
\hline & & Land Cover & $1 \mathrm{~km}$ & Yearly \\
\hline & & Albedo & $1 \mathrm{~km}$ & 16-day \\
\hline \multirow{5}{*}{ Forcing Dataset III } & GLDAS & Surface meteorology & $\frac{1}{4}{ }^{\circ}$ & Instantaneous, interpolated \\
\hline & \multirow{4}{*}{ MODIS } & LST/Emissivity & $1 \mathrm{~km}$ & Instantaneous \\
\hline & & LAI & $1 \mathrm{~km}$ & 8-day \\
\hline & & Land Cover & $1 \mathrm{~km}$ & Yearly \\
\hline & & Albedo & $1 \mathrm{~km}$ & 16-day \\
\hline
\end{tabular}

corresponding meteorological data. Since measurements of the ground heat flux $\left(G_{0}\right)$ are not directly available at most of the CEOP sites ${ }^{2}$, the prediction of the ground heat flux by SEBS is not assessed in this study.

In the following sections, further details on actual site characteristics and the processing of MODIS data is discussed.

\subsection{In-situ data from CEOP and site characteristics}

The Enhanced Observing Period 2001 (EOP1) provides hourly observation of surface meteorological variables and energy fluxes from July $1^{\text {st }}$ through September $30^{\text {th }}$ in 2001. Eleven basic variables are required by SEBS from the CEOP dataset. These variables fall into two categories: surface meteorological and radiative data (i.e., air temperature, pressure, humidity, wind speed, downward and upward longwave radiation, downward and upward shortwave radiation) and surface energy flux data (i.e., net radiation, sensible and latent heat fluxes) which are used to validate the model predictions. There are only eight stations (6 sites) from CEOP EOP-1 that meet the data requirements of the SEBS model ${ }^{3}$, with site names and characteristics (including country, location, land classification and climate type) listed in Table 3 . The six sites are distributed across five countries and three continents. The dominant land cover types are listed in the last column in Table 3.

The climate types of the selected CEOP sites (see) with their names are listed in the $4^{\text {th }}$ column in Table 3. The six sites fall into three broad climate types and four different vegetation covers. Brief descriptions of each site are given below, with further details available from http://www.eol.ucar.edu/projects/ceop/dm/.

\section{a Cabauw (grassland)}

The Cabauw tower site is located in the central region of the Netherlands. The surroundings are flat and consist of meadows which are used for grazing and for the production of hay (Beljaars and Bosveld 1997). The grass at the

2 Soil heat flux measurements at $5 \mathrm{~cm}$ and $10 \mathrm{~cm}$ are available at two of the eight chosen stations, but require correction to the ground surface to be used as $G_{0}$. Five of the eight stations have no observations of soil heat flux. Only one station provides sufficient ground heat flux measurements.

3 Southern Great Plains (SGP) sites in CEOP EOP1 are excluded from this study, but are the focus of ongoing investigations. 
Table 3. Characteristics of the reference sites.

\begin{tabular}{|l|l|l|c|l|}
\hline Site Name & \multicolumn{1}{|c|}{ Country } & \multicolumn{1}{|c|}{ Lat/Lon $\left(^{\circ}\right)$} & KoppenClimate* & $\begin{array}{l}\text { Dominant Land Cover } \\
\text { (DLC) }\end{array}$ \\
\hline Cabauw & The Netherlands & $(51.97,4.93)$ & $\mathrm{C}$ & Grassland \\
\hline Lindenberg & Germany & $(52.17,14.12)$ & $\mathrm{C}$ & Grassland \\
\hline Bondville & USA & $(40.01,-88.29)$ & $\mathrm{D}$ & Cropland (Corn) \\
\hline Rondonia & Brazil & $(-10.01,-61.93)$ & $\mathrm{A}$ & Rain forest \\
\hline Manaus & Brazil & $(-2.61,-60.21)$ & $\mathrm{A}$ & Rain forest \\
\hline $\begin{array}{l}\text { BERMS } \\
\text { (Old_Aspen) }\end{array}$ & Canada & $(53.63,-106.20)$ & $\mathrm{D}$ & $\begin{array}{l}\text { Forest } \\
\text { (Old_Aspen) }\end{array}$ \\
\hline $\begin{array}{l}\text { BERMS } \\
\text { (Old_Jack_Pine) }\end{array}$ & Canada & $(53.92,-104.69)$ & $\mathrm{D}$ & $\begin{array}{l}\text { Forest } \\
\text { (Old_Jack_Pine) }\end{array}$ \\
\hline $\begin{array}{l}\text { BERMS } \\
\text { (Old_Black_Spruce) }\end{array}$ & Canada & $(53.99,-105.12)$ & $\mathrm{D}$ & $\begin{array}{l}\text { Forest } \\
\text { (Old_Black_Spruce) }\end{array}$ \\
\hline
\end{tabular}

* A: tropical; B: dry; C: warm temperate rainy climates and mild winters; D: cold forest climates and severe winters; E: polar; H: highland.

measuring field is kept at a height of approximately $8 \mathrm{~cm}$ by frequent mowing. The vegetation cover at Cabauw is close to $100 \%$ all year. Caubauw is one of the sites in the Baltic Sea Experiment (BALTEX) and has been demonstrated to be a useful case study for midlatitude homogeneous grassland within the Project for Intercomparison of Land-Surface Parameterization Schemes (PILPS) framework (Chen et al. 1997; Henderson-Sellers et al. 1995).

\section{$b \quad$ Lindenberg (mixed forest and grassland)}

Lindenberg is located in the east of Germany and also forms a member site of BALTEX. The climate type of Lindenberg is the same as Cabauw, with heterogeneous land use dominanted by a mixture of forest (43\%) and agricultural farmland (45\%) with a number of small and medium-sized lakes (7\%) (Beyrich and Adam 2004). The Lindenberg data for CEOP EOP-1 include the near surface measurements carried out at GM Falkenberg, which represent only the farmland (low vegetation, grassland) part of the area.

\section{c Bondville (cropland)}

Bondville is located in central Illinois, USA and is both a member site of the GAPP program (GEWEX America Prediction Project) and a member of the AmeriFlux network. The climate of Bondville is temperate continental and the vegetation type in the summer of 2001 was predominantly corn. Although the MODIS land classification shows the land cover at Bondville is homogeneous, the MODIS pixel over this site is actually a mixture of corn and soybean since there is a companion site at Bondville which is located $400 \mathrm{~m}$ north of the major site and is planted with opposite crop in corn/soybean rotation ${ }^{4}$. It is the only representative agricultural site from the six CEOP sites used here.

\section{$d$ Rondonia and Manaus (tropical forest)}

Both Rondonia and Manaus are in Brazil and are member sites of the Large Scale BiosphereAtmosphere Experiment in Amazonia (LBA). The vegetation covers for the two sites are primarily forest and rain forest (Andreae et al. 2002). They are of tropical humid climate with a dry season in winter. The frequent cloud cover makes it extremely difficult to measure the reflectance in the visible and near infrared bands from satellites, which in turn leads to more uncertainties in $L A I$ estimation. Both

4 From AmeriFlux: http://public.ornl.gov/ameriflux/ Site_Info/siteInfo.cfm?KEYID=us.bondville.02. 
sites have a rather high $L A I$ in the whole 3 months, which ranges from 5 to 7 .

e BERMS (cold forest)

The study area of the Boreal Ecosystem Research and Monitoring Sites (BERMS) in CEOP consist of three individual stations with vegetations covers of Old Aspen, Old Jack Pine and Old Black Spruce respectively. Old Aspen is deciduous while the other two are needle leaf forest, which inhabit the cold mid-latitude climate typical of BERMS. All the in-situ tower flux measurements from each of the three stations during CEOP EOP-1 were used in our study.

\subsection{Surface meteorological data from GLDAS}

The surface meteorological data in Forcing Dataset III were extracted from the GLDAS forcing dataset over each CEOP site. The surface forcing fields from GLDAS is an integration of observational fields and outputs from the atmospheric data assimilation system (ADAS) component of a weather forecast and analysis system (Rodell et al. 2004). Six basic variables are required by SEBS from the GLDAS forcing dataset, including the air temperature, humidity, pressure, wind speed, downward longwave and incident shortwave radiation. The surface meteorological and radiative variables from GLDAS were interpolated in the time domain to match with the instantaneous MODIS LST. GLDAS forcing, in combination with the necessary MODIS data, are used to form Forcing Dataset III which is more operationally available than the Dataset I and II.

\subsection{Data from MODIS}

To estimate the terrestrial $E T$ globally, operational remotely sensed data need to be utilized, specifically $L A I$, vegetation fraction, surface broadband emissivity and Albedo which are derived from MODIS data. These MODIS based remote sensing measurements can provide SEBS the required land physical parameters: LAI (Myneni et al. 2002), albedo (Schaaf et al. 2002), vegetation index (Huete et al. 2002), land classification (Friedl et al. 2002) and land surface temperature and emissivity (Wan et al. 2004). In Forcing Datasets II and III, MODIS data, such as MODIS LST and al- bedo, are incorporated to form a more operational forcing data for SEBS.

a LAI, vegetation fraction and land cover

$L A I$ describes an important structural property of a plant canopy, defined as the one sided green leaf area per unit ground area (Chen and Black 1992). The MOD15 Leaf Area Index $(L A I)$ is a $1 \mathrm{~km}$ global data product updated using an 8-day window (Myneni et al. 2002). Collection 4 of MODIS $L A I$ product has been evaluated by (Cohen et al. 2003) and (Wang et al. 2004). Some abrupt changes of the MODIS derived $L A I$ were found over the CEOP reference sites during the summer season of 2001, especially for the forest sites in this study. When vegetation densities are high, there is less confidence in the output value of the assigned $L A I$ since the reflectance belongs to the "saturation domain" and the low values of $L A I$, such as in Amazon forest, may also be caused by frequent cloud contamination (Myneni et al. 2002). To minimize the instability of the MODIS LAI time series extracted from a single pixel, an averaged $L A I$ over a 3 by 3 pixel box centered on each CEOP reference site is used as a surrogate. The dynamics of MODIS derived $L A I$ from a 3 by 3 pixel box corresponding to each of the 8 CEOP stations in summer of 2001 are shown in Fig. 1. The $L A I$ in Lindenberg, which is a mixure of grassland and forest, is found to be much lower than that in the grassland Cabauw. The low $L A I$ estimates from MODIS at Lindenberg may be caused by the misclassification of the vegetation cover or the algorithm of MODIS LAI itself. One real point that needs attention is the temporal/spatial consistency of the MODIS datasets. The abrupt change of $L A I$, which can be identified in Fig. 1, can not be explained by the growing of the plants except the old aspen station. Even forest fire can't give a reasonable explanation. It might be caused by the MODIS LAI data product itself. Clearly, the sacrifice of spatial resolution to achieve a smoothed time series of $L A I$ may be problematic if the land cover of the site footprint is highly heterogeneous. To maintain consistency with the hourly observation data from CEOP, the 8-day $L A I$ values are linearly interpolated to the daily scale. Vegetation fraction is computed based on $L A I$ with an assumption of a particular leaf angle distribution for a given 


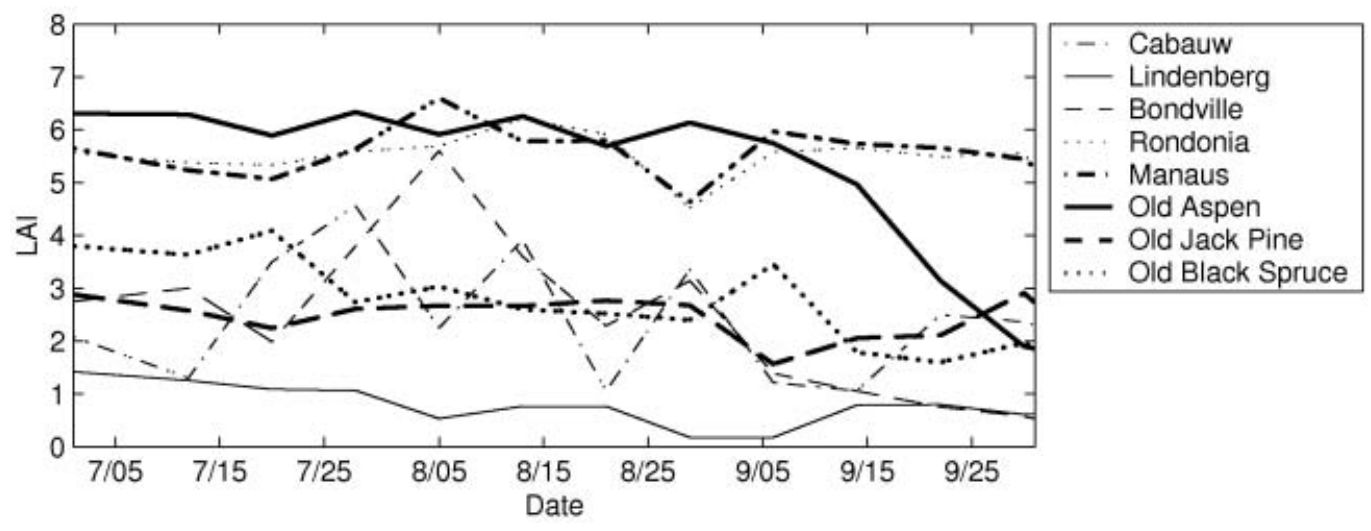

Fig. 1. LAI dynamics derived from MODIS at CEOP stations.

vegetation type which can be obtained from MODIS land cover data product.

\section{$b$ Albedo}

The MODIS based albedo product MOD43 (Schaaf et al. 2002) is used in Forcing Datasets II and III. There are two different albedo provided by MODIS: black-sky and white-sky albedo. Ideally, these require column water vapor and aerosol concentration to force the atmospheric radiative transfer model which partitions the direct and diffuse incident solar energy to determine the overall surface albedo. In this current study, the black-sky and whitesky albedo are averaged to derive the overall surface albedo, since the parameters required to do the atmospheric radiative correction are not readily available.

The simplification of the albedo estimation in vegetated areas is not expected to introduce significant error in flux estimation. Betts and Ball (1997), undertaking a study of surface Albedo in Boreal forest, formulate the relation between daily averaged albedo and the diffuse flux ratio of insolation:

$$
\bar{\alpha}=A+B \cdot\left(\frac{\overline{D_{\downarrow}}}{\overline{S_{\downarrow}}}\right)
$$

where $\bar{\alpha}$ is the daily averaged surface albedo, $A$ and $B$ are two coefficients derived by regression, $\overline{D_{\downarrow}}$ is the daily diffuse incident solar energy and $\overline{S_{\downarrow}}$ is the daily total incident solar energy. The coefficient $A$ varies with different vegetation types. $B$ is found to be in the range of -0.009 to -0.018 for grass, aspen, black spruce and jack pine when there is no snow cover (Betts and Ball 1997). The low value of coefficient $B$ implies that the diffuse flux ratio of insolation does not play a significant role in the overall surface albedo. Absolute value of coefficient $B$ is less than 0.018 , which means that the error of the estimated overall albedo is within 0.009 if the direct and diffuse solar radiation ratio is assumed to be $1: 1$. The assumption of equal direct and diffuse solar radiation is equivalent to our simple averaging method.

\section{c Broadband emissivity and LST}

Right now, there is no measurement of the broadband emissivity at site scale from the CEOP reference sites. The only possible way to obtain the emissivity is to get it from the satellite data product, such as MODIS data, although it is at a larger spatial scale. The broadband emissivity is derived from the daily narrow band emissivity of MODIS bands 29, 31 and 32 (Wan and Li 1997; Wan et al. 2004). The formula of the emissivity conversion (pers. comm. Dr. Z. Wan 2004) is as follows:

$$
\varepsilon=0.2031 \cdot \varepsilon_{29}-0.0648 \cdot \varepsilon_{31}+0.8602 \cdot \varepsilon_{32}
$$

where $\varepsilon$ is the broadband emissivity and $\varepsilon_{29}, \varepsilon_{31}$ and $\varepsilon_{32}$ are the narrow band emissivities for bands 29,31 and 32 respectively. The broadband emissivity is interpolated linearly to fill in the gaps in Forcing Dataset I when the MODIS derived broadband emissivity is absent in order to match up with the CEOP dataset at times other than MODIS overpass.

For Forcing Dataset I, in-situ surface temperature observations are only available at Bond- 
ville and Rondonia. For locations where the surface temperature $\left(T_{s}\right)$ is not observed directly, it is estimated indirectly from the upward longwave radiation $\left(R_{l w u}\right)$ and downward longwave $\left(R_{l w d}\right)$, using a correction for the broadband emissivity:

$$
T_{s}=\left(\frac{R_{l w u}-(1-\varepsilon) \cdot R_{l w d}}{\varepsilon \sigma}\right)^{1 / 4}
$$

which is derived from the longwave radiation balance equation.

The land surface temperature in Forcing Datasets II and III is obtained directly from the $1 \mathrm{~km}$ instantaneous MODIS (onboard TERRA) LST product.

\section{Results}

Usually, remote sensing based $E T$ model is evaluated in a very short time period; typically, the experiments are within days or weeks. In our study, 8 stations which are of different land cover and climate zones are used to evaluate our ET model in the 3 month period. We don't worry about the number of observations in our study. In addition, $r R M S E$ (relative Root Mean Square Error) is also employed to assess the performance of the ET modeling. Because of the large uncertainty in ET modeling or even in the $E T$ measurement on ground, it is hard to set a standard to judge whether or not a model is good. Instead, the usual way is to have a look at the bias and RMSE to see if it is comparable with those for $E T$ measurement. Experiment showed that, two collocated ET measurement equipments may give a deviation of about $10-15 \%$ on $E T$ (Lloyd et al. 1997).

Evapotranspiration predictions were obtained for each of the three different forcing datasets listed in Table 2. In this section, the ET estimation at both the tower and satellite scales are presented and analyzed. SEBS predicted ET which was based mainly on CEOP observations is examined at daily and 10-day time scales. The MODIS based instantaneous ET estimation from Forcing Datasets II and III is also evaluated with the CEOP tower flux measurements.

\subsection{Tower scale estimation}

SEBS model produced hourly predictions of daytime surface energy fluxes for the eight CEOP stations described above. Intercompari- son of the remaining heat fluxes is undertaken at daily and 10-day time scales.

\section{a Daily comparison}

Daily averages of the energy fluxes for each of the eight stations are presented in Fig. 2. Since the SEBS model does not predict the surface energy fluxes at night, fluxes are only calculated during the daytime, specifically from 5:00 a.m. through 6:00 p.m. in local time at each site. The time period in daytime is chosen to ensure that all valid data can be used in the analysis. In high latitude region in north hemisphere, there is a much longer daytime in summer. To filter out periods of inclement weather (cloud affected or rainy days), the daily average is computed only for those days when both the observations and the model predictions are available for more than 4 hours per day. The numbers of available days in the three months and the bias of SEBS predicted daily heat fluxes are computed for each station and labeled in each panel in Fig. 2.

The RMSE of the daily average of the net radiation estimation is within $20 \mathrm{~W} \mathrm{~m}^{-2}$ for all eight stations, since the four components of radiation flux measurements $\left(R_{s w d}, R_{s w u}, R_{l w d}\right.$ and $R_{l w u}$ ) are used directly in this application of SEBS to derive net radiation. The largest bias of daily ET estimation is found in BERMS (Old Aspen) with a negative bias of $28 \mathrm{~W} \mathrm{~m}^{-2}$; the largest sensible heat bias is at Rondonia which presents a positive bias of $29 \mathrm{~W} \mathrm{~m}^{-2}$. Both are forest sites. No systematic bias of $E T$ estimates is found at the 8 different sites.

Statistics of the heat flux comparison between SEBS predictions and CEOP observations on daily scale are presented in Table 4. Specifically the root mean square ( $R M S E)$ error and the relative RMSE ( $R R M S E$ ) of the corresponding SEBS predication, the mean of the observed and SEBS derived daily daytime averaged surface heat fluxes ( $H$ and $L E$ ), and the daytime averaged evaporative fraction from CEOP observation and SEBS estimates are listed in Table 4 for all eight stations. The bias of model predictions on $H$ and $L E$ for each site can be found in the corresponding panel in Fig. 2 . The $r R M S E$ is chosen here as one of the criteria together with root mean squared error $(R M S E)$, to evaluate the accuracy of model prediction and it is defined following Conte et al. 

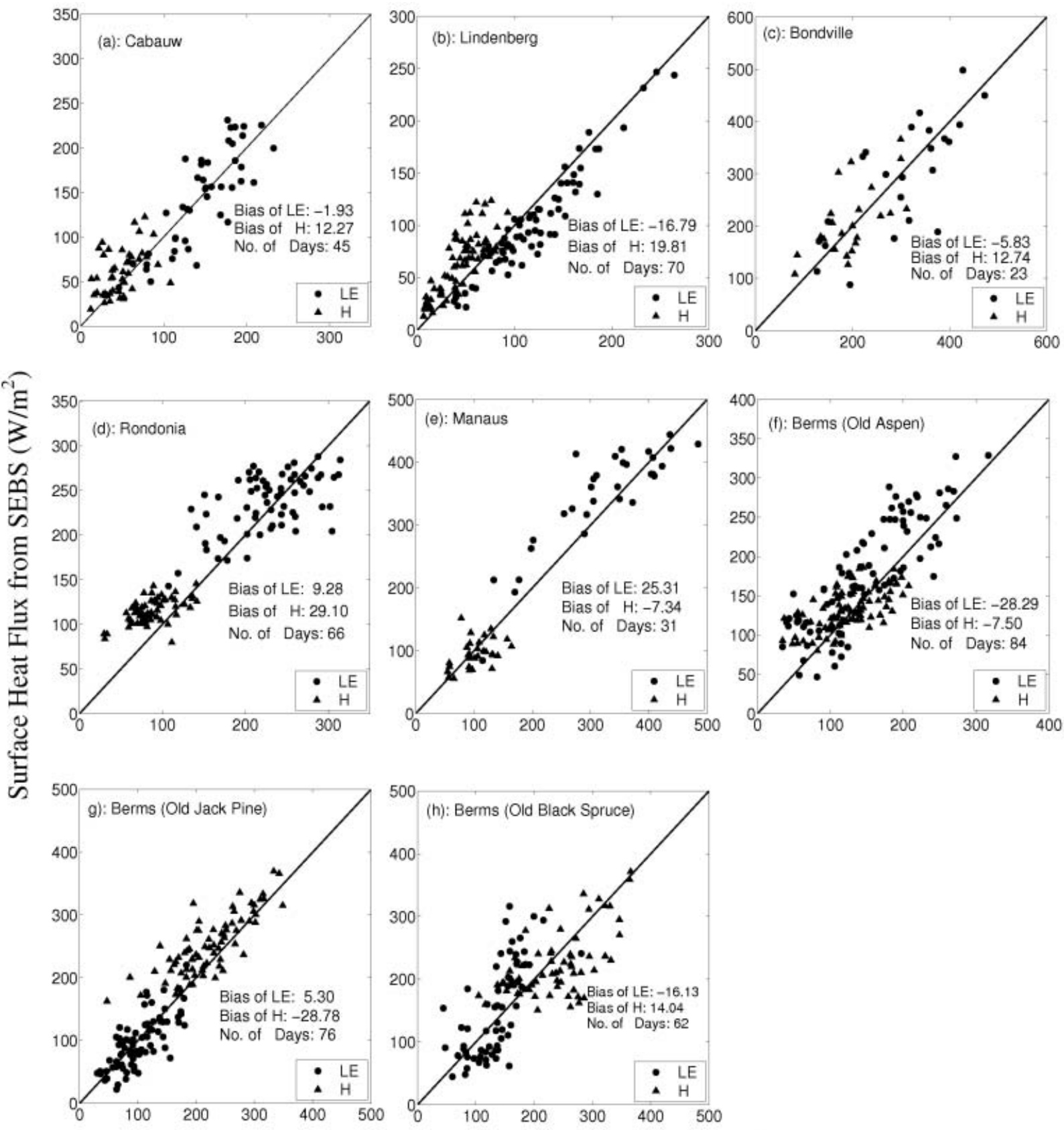

\section{Surface Heat Flux from Observation $\left(\mathrm{W} / \mathrm{m}^{2}\right)$}

Fig. 2. Comparison of daily (5 H-18 $\mathrm{H}$ in local time) averaged energy fluxes.

(1986) as:

$$
r R M S E=\frac{R M S E}{\text { Mean(Observation })}
$$

The performance of SEBS in different land cover and climatic classifications is assessed mainly based on the two criteria mentioned above. The minimum RMSE of daily daytime averaged $L E$ estimation is $23 \mathrm{~W} \mathrm{~m}^{-2}$ at Lindenberg, which is a grassland site. The corresponding $r R M S E$ of daily $L E$ estimation at this site is $18.9 \%$. For the other grass site, Cabauw, the 


\begin{tabular}{|c|c|c|c|c|c|c|c|c|}
\hline 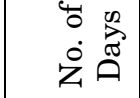 & $\stackrel{8}{f}$ & 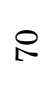 & & 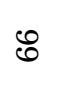 & $\vec{\omega}$ & $\infty_{\infty}$ & $\stackrel{0}{L}$ & ชิ \\
\hline 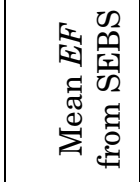 & $\begin{array}{l}\infty \\
\stackrel{0}{0} \\
0\end{array}$ & $\begin{array}{l}\stackrel{1}{1} \\
\text { ర్ } \\
0 \\
0\end{array}$ & $\begin{array}{l}\mathcal{N} \\
\infty \\
\infty \\
0 \\
0 \\
0\end{array}$ & $\begin{array}{l}\mathbb{N} \\
\hat{\sigma} \\
0 \\
0\end{array}$ & \begin{tabular}{l}
\multicolumn{1}{c}{} \\
$\infty$ \\
\\
0
\end{tabular} & $\begin{array}{l}0 \\
20 \\
10 \\
0\end{array}$ & 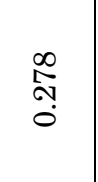 & $\begin{array}{l}\text { oे } \\
\text { ợ } \\
0\end{array}$ \\
\hline 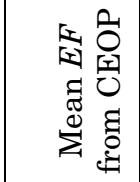 & $\begin{array}{l}0 \\
\stackrel{0}{\circ} \\
\\
0\end{array}$ & 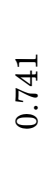 & $\begin{array}{l}1 \\
0 \\
0 \\
0 \\
0\end{array}$ & 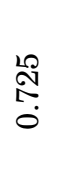 & $\begin{array}{l}\infty \\
\stackrel{2}{a} \\
\vdots \\
0\end{array}$ & 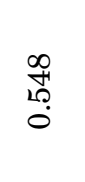 & $\begin{array}{l}20 \\
\stackrel{20}{0} \\
0\end{array}$ & 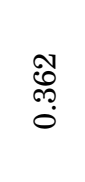 \\
\hline 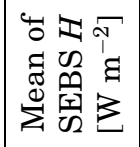 & (8) & $\overline{6}$ & 음 & $\stackrel{H}{\beth}$ & 20 & 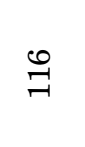 & ब. & 点 \\
\hline 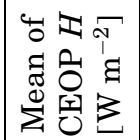 & 尔 & F & 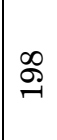 & 100 & $\underset{\sim}{\stackrel{\gamma}{0}}$ & $\stackrel{\sharp}{\underset{I}{J}}$ & ๙ิ & ๙ิ \\
\hline 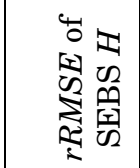 & $\begin{array}{l}0 \\
+ \\
\infty \\
0 \\
10\end{array}$ & 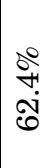 & $\begin{array}{l}\stackrel{0}{0} \\
\stackrel{0}{\circ}\end{array}$ & $\begin{array}{l}\stackrel{\diamond}{\sharp} \\
\stackrel{+}{+} \\
\forall\end{array}$ & $\begin{array}{l}\text { \&̊ } \\
6 \\
\text { ลิ }\end{array}$ & $\begin{array}{l}\stackrel{\circ}{0} \\
\text { ஸे } \\
\stackrel{\leftrightarrow}{\text { N }}\end{array}$ & 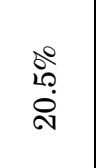 & $\begin{array}{l}\stackrel{8}{0} \\
\dot{d} \\
\text { in }\end{array}$ \\
\hline 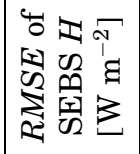 & $\widehat{N}$ & $\stackrel{\leftrightarrow}{\sim}$ & م & 然 & $\stackrel{\infty}{\sim}$ & กิ & $\stackrel{10}{4}$ & น \\
\hline 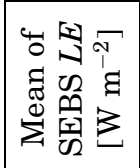 & $\underset{\sim}{\stackrel{H}{\prime}}$ & 음 & ๙ֶ. & 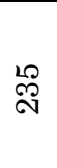 & $\underset{\text { H }}{H}$ & స̃ & $\underset{0}{0}$ & $\stackrel{\infty}{=}$ \\
\hline 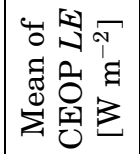 & $\underset{\sim}{\mathscr{I}}$ & $\stackrel{\stackrel{\rho}{二}}{\sim}$ & 尽 & $\begin{array}{l}\mathscr{N} \\
\text { Nิ }\end{array}$ & $\begin{array}{l}\infty \\
\stackrel{\infty}{1}\end{array}$ & [20 & 음 & 蔦 \\
\hline 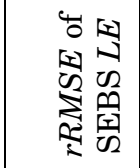 & $\begin{array}{l}\stackrel{0}{0} \\
\dot{\circ} \\
\dot{\sim}\end{array}$ & $\begin{array}{l}\stackrel{0}{\sigma} \\
\infty \\
-1 \\
-1\end{array}$ & 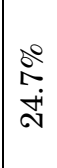 & 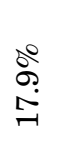 & 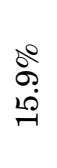 & $\begin{array}{l}\text { ô } \\
\text { के }\end{array}$ & $\begin{array}{l}\infty 0 \\
\infty \\
\infty \\
\text { No }\end{array}$ & 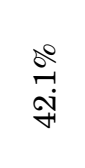 \\
\hline 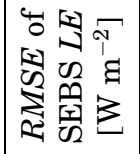 & ஓి & ลิ & 芯 & 아 & 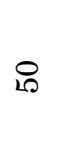 & $\stackrel{\infty}{+}$ & న & $\stackrel{0}{10}$ \\
\hline 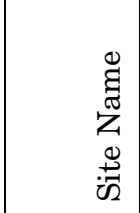 & 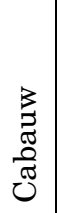 & 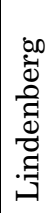 & 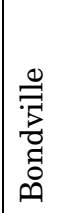 & 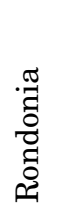 & 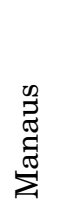 & 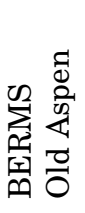 & 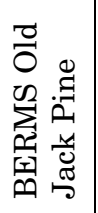 & 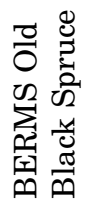 \\
\hline
\end{tabular}


$r R M S E$ of daily $L E$ estimation is $20.6 \%$, which shows no significant difference with that of Lindenberg. It demonstrates that SEBS works pretty well to predict the $E T$ over the grassland. The largest $R M S E$ of daily $L E$ prediction from SEBS is found at Bondville (corn site) with a value as high as $74 \mathrm{~W} \mathrm{~m}^{-2}$, the $r R M S E$ at Bondville, however, is only $24.7 \%$. Considering that it has a much higher daily averaged $E T$ in its rapid growing period in summer and the site heterogeneity which will be discussed later in Section 5, rRMSE of $24.7 \%$ at the crop site is a reasonable model prediction. The least accurate reproduction of daily $L E$ relative to insitu measurements is found at the Old Black Spruce station of BERMS, with a value of 42.1\%. For the other two stations at BERMS (Old Aspen and Old Jack Pine), the rRMSE of the daily $L E$ are $31.9 \%$ and $28.8 \%$ respectively. One of the explanations for the high $r R M S E$ of the daily $L E$ estimation over the BERMS region is that the mean daily $L E$ of the CEOP observation is quite low in the cold region, in the range of 102 to $151 \mathrm{~W} \mathrm{~m}^{-2}$, for the Boreal forest. Considering the $r R M S E$ of the daily averaged $L E$ for each site, the accuracy of the $L E$ estimation for tropical forest is the highest, then the grasslands, followed by the corn site. The $L E$ estimation for the Boreal forest in the high latitude region has the largest uncertainty from the perspective of $r R M S E$.

The $r R M S E$ of the daily sensible heat $(H)$ estimation are generally higher than those of daily $L E$ prediction except for the three BERMS stations. One reason may be that the mean values of $H$ are relatively larger at BERMS, considering that the three BERMS stations have the lowest mean evaporative fractions $(E F)$ among all the stations. The mean $E F$ in Table 4 is defined as:

$$
\operatorname{Mean}(E F)=\frac{\sum_{i=1}^{92} L E_{i}}{\sum_{i=1}^{92}\left(L E_{i}+H_{i}\right)}
$$

$L E_{i}$ and $H_{i}$ are the daytime averaged surface heat fluxes for each day during EOP-1 and the $i$ th data is not used in the calculation when the data is not available. The comparison of the mean $E F$ shows that estimates from SEBS agree very well with those from observations and exhibit no significant bias. Both the model predicted and observed mean evaporative frac- tions at the two tropical sites are above 0.65 during the summer of 2001, which is reasonable considering the climatic conditions in the Amazon, where water supply is sufficient for sustained forest growth. Cabauw and Lindenberg also have very high mean $E F$ in summer. For the Cabauw grassed site, the soil is reported to be at field capacity all year long and the evapotranspiration is seldom limited by the water supply (Chen et al. 1997). The largest bias of the mean $E F$ estimation is 0.111 (negative bias) at Lindenberg. Generally, the prediction of mean $E F$ from SEBS illustrates a close agreement with that from observations.

From Fig. 2 and Table 4, it is shown that both the climate and the vegetation type have an important control over the daytime surface heat flux patterns. It is true that similar conclusion has been made by others before (Lafleur and Rouse 1995; Bridgham et al. 1999), basically at a longer time scales, such as seasonal or annual. The finding here is still meaningful since it is confirmed again by a model (SEBS) which is driven by different input data (combination of surface meteorology and satellite data) to predict the terrestrial ET. The assessment of the model's performance in reproducing the different $E T$ patterns under different climate and vegetation types is essential to expand the ET predictions from site scale to the scales of satellite data. The SEBS model is observed to reproduce the patterns of the daily surface heat flux under diverse climate conditions and vegetation types. While estimates of the sensible and latent heat fluxes in SEBS for the Boreal forests are not as accurately reproduced, such vegetated stands represent some of the most difficult surface types over which to model $E T$, due to their strong coupling with the atmosphere (Margolis and Ryan 1997) and uncertainties in retrieving required variables. However, for the most part (6 out of the 8 sites), estimates of the daytime $E T$ agree within $50 \mathrm{~W} \mathrm{~m}^{-2}$ or $20 \%$.

\section{$b$ Ten day averaged comparison}

The satellite based modeling of $E T$ is different with those based on mass balance in land surface models, hydrological models or ecological models. Instead, it is based on instantaneous energy balance. There is a gap between the time scale of $E T$ prediction based on satel- 
lite and the requirement of its related application, for example in draught monitoring, agricultural yield estimation. The applications often need $E T$ estimation in different levels of time scale, ranging from hourly to monthly. The satellite based instantaneous ET predictions need to be expanded in temporal domain. A 10-day global ET prediction based on satellite observations is part of the planned ET data product, which can bridge the temporal gap between remotely sensed observations and the needs of hydrological, climatological and agricultural studies. Thus, testing the ET model at different time scales where in situ measurement is available is very helpful to enhance the later application of the ET data.

Ten day cloud free daytime averaged sensible and latent fluxes from SEBS predictions and the corresponding CEOP measurements are shown in the bar plots of Fig. 3. Surface heat flux at 10-day time scale was examined since remotely sensed data from MODIS, especially land surface temperature, is unlikely to be available over a spatially continuous extent at the daily time scale. Daytime is defined from 5:00 a.m. through 6:00 p.m. in local time for each site. Results are not presented when either the CEOP observations or the model predictions are unavailable during the 10-day period. Similar to Fig. 2, net radiation comparison between the SEBS model prediction and the CEOP observation are not shown, since the deviation of 10-day cloud free averaged net radiation predictions is below $20 \mathrm{~W} \mathrm{~m}^{-2}$. Figure 3 presents the bar plots comparing heat fluxes from SEBS and CEOP observations. The two curves in each panel show the 10-day cloud free daytime averaged evaporative fractions $(E F)$ derived from the SEBS model outputs and the CEOP observation.

The variations of the evaporative fraction at 10-day scale can also be examined from Fig. 3. Cabauw, Lindenberg, Rondonia and Manaus show relatively flat curves of evaporative fraction, while the evaporative fraction curves show more temporal variability at the other 4 stations. At the Bondville station and 3 BERMS sites (Old Aspen, Old Jack Pine and Old Black Spruce), the peak $E F$ is found towards mid-late July, with $E F$ tending to decrease after this time. The low temporal variability of evapotranspiration at stations (Cabauw, Lindenberg,
Rondonia and Manaus) may be due to the sufficient water supply. The deviation of the predicted and observed $L E$ in July at Lindenberg is much greater than the other two months. The underestimation of $L E$ in SEBS will be discussed further in the Section 5.

The $E F$ patterns at the Old Aspen forest (panel f) are dissimilar to those at the other BERMS sites (panel g,h) in that the Aspen forest exhibits the largest intra-seasonal variation of the three BERMS stations, with the evaporative fraction 0.2 units larger than the others during July, despite all located in the Boreal forest climate zone. One possible reason is that properties of the species of the cold forest are different, for example, different vegetation height corresponding to different roughness length in the momentum and turbulent heat transfer. The ET prediction from SEBS verifies again that deciduous species represents a higher water flux than the coniferous species in Boreal forest, which was revealed by previous Boreas study (Margolis and Ryan 1997). Another reason is that the Old Aspen forest in BERMS consistently has the highest $L A I$ in the 3 months among the three forest stations (refer to Fig. 1). In July and August, the $L A I$ at Old Aspen forest is nearly 3 times that at Old Jack Pine forest and 1.5 times the Old Black Spruce forest. In September, the $L A I$ at all three forest stations begins to decrease, but the $L A I$ at Old Aspen remains significantly larger than that of the other two stations until the end of September. $L A I$, together with vegetation fraction, have a direct impact on the partitioning of available energy into sensible and latent heat fluxes in the SEBS model and are amongst several of the required model parameters which can be provided from remote sensing data.

Table 5 shows the statistics of the heat fluxes and evaporative fraction intercomparison at the 10-day time scale. The RMSE and model bias of the 10-day averaged heat fluxes from SEBS have been improved significantly from those of the daily averaged heat fluxes for all 8 CEOP stations. The 10-day averaged model predicted heat fluxes from SEBS have the largest deviation at Bondville (a corn site) with a RMSE of $47 \mathrm{~W} \mathrm{~m}^{-2}$ for $L E$ and $43 \mathrm{~W} \mathrm{~m}^{-2}$ for $H$ (see Table 5). The rRMSE of $L E$ and $H$ at Bondville are $14.0 \%$ and $25.4 \%$ respectively, a result of 


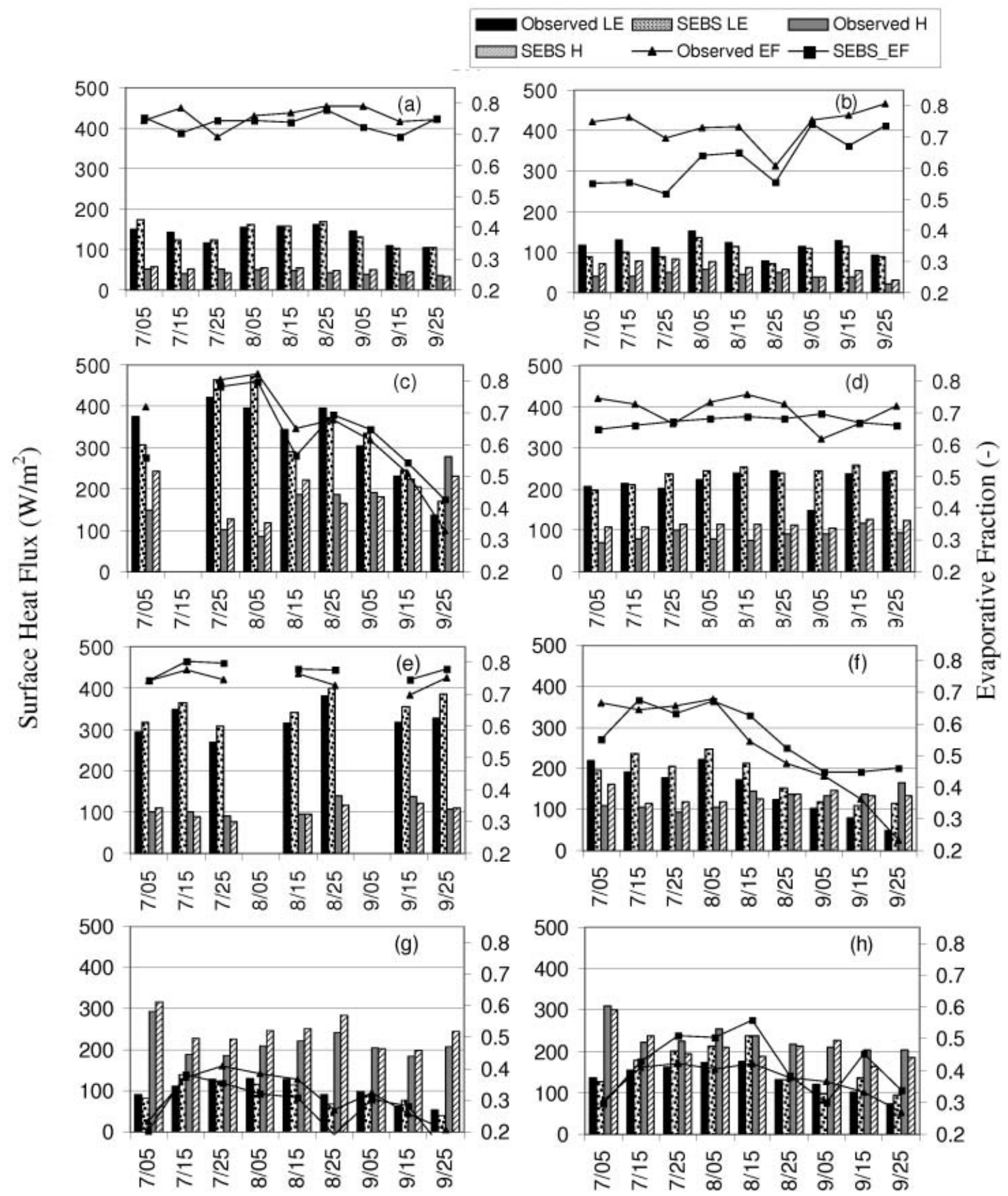

Date in 2003

Date in 2003

Fig. 3. Comparison of 10-day cloud-free daytime averaged Heat Fluxes (a: Cabauw, b: Lindenberg, c: Bondville, d: Rondonia, e: Manaus, f: BERMS (Old_Aspen), g: BERMS (Old_Jack_Pine), h: BERMS (Old_Black_Spruce)). 
Table 5. Statistics of the daytime Heat Fluxes and Evaporative Fraction $(E F)$ at the 10-day scale.

\begin{tabular}{|l|c|c|c|c|c|c|c|c|c|}
\hline Site Name & $\begin{array}{c}R M S E \text { of } \\
\text { SEBS } L E \\
{\left[\mathrm{~W} \mathrm{~m}^{-2}\right]}\end{array}$ & $\begin{array}{c}\text { Mean of } \\
\text { CEOP } L E \\
{\left[\mathrm{~W} \mathrm{~m}^{-2}\right]}\end{array}$ & $\begin{array}{c}\text { Mean of } \\
\text { SEBS } L E \\
{\left[\mathrm{~W} \mathrm{~m} \mathrm{~m}^{-2}\right]}\end{array}$ & $\begin{array}{c}R M S E \text { of } \\
\text { SEBS } H \\
{\left[\mathrm{~W} \mathrm{~m}^{-2}\right]}\end{array}$ & $\begin{array}{c}\text { Mean of } \\
\text { CEOP } H \\
{\left[\mathrm{~W} \mathrm{~m}^{-2}\right]}\end{array}$ & $\begin{array}{c}\text { Mean of } \\
\text { SEBS } H \\
{\left[\mathrm{~W} \mathrm{~m}^{-2}\right]}\end{array}$ & $\begin{array}{c}\text { Mean } \\
E F \text { from } \\
\text { CEOP }\end{array}$ & $\begin{array}{c}\text { Mean } \\
E F \text { from } \\
\text { SEBS }\end{array}$ & $\begin{array}{c}\text { No. } \\
\text { of } \\
\text { Data }\end{array}$ \\
\hline Cabauw & 12 & 138 & 138 & 8 & 43 & 48 & 0.760 & 0.739 & 9 \\
\hline Lindenberg & 18 & 116 & 100 & 23 & 42 & 61 & 0.734 & 0.620 & 9 \\
\hline Bondville & 47 & 325 & 331 & 43 & 175 & 186 & 0.650 & 0.639 & 8 \\
\hline Rondonia & 36 & 217 & 236 & 27 & 88 & 114 & 0.709 & 0.674 & 9 \\
\hline Manaus & 35 & 321 & 353 & 13 & 110 & 102 & 0.743 & 0.774 & 7 \\
\hline $\begin{array}{l}\text { BERMS } \\
\text { (Old } \\
\text { Aspen) }\end{array}$ & 35 & 149 & 177 & 23 & 125 & 132 & 0.542 & 0.573 & 9 \\
\hline $\begin{array}{l}\text { BERMS } \\
\text { (Old Jack } \\
\text { Pine) }\end{array}$ & 16 & 99 & 93 & 31 & 215 & 243 & 0.315 & 0.277 \\
\hline $\begin{array}{l}\text { BERMS } \\
\text { (Old Black } \\
\text { Spruce) }\end{array}$ & 33 & 136 & 157 & 30 & 231 & 213 & 0.371 & 0.425 \\
\hline
\end{tabular}

relatively high values of surface fluxes at these sites (see panel c in Fig. 3). RMSEs of $L E$ are below $40 \mathrm{~W} \mathrm{~m} \mathrm{~m}^{-2}$ at all remaining stations, while for $H$, the RMSEs are below $32 \mathrm{~W} \mathrm{~m}^{-2}$, demonstrating that the predictions of heat fluxes from SEBS are in good agreements with the observations at 10-day time scale. The mean evaporative fractions at 10-day time scale in Table 5 show no significant difference with those in Table 4, which is at daily scale. The slight difference is due to the fact that some daily data points may have been discarded during the aggregation process.

The 10-day cloud free daytime averaged energy fluxes and evaporative fraction determined by SEBS are in closer agreement with observations at all eight CEOP stations than what estimated at the daily scale. The latitudinal and intra-seasonal variation of the heat fluxes caused by vegetation types and climate conditions can be reproduced very well by SEBS. For example, the forest in Amazon demonstrates different patterns of evapotranspiration than the Boreal forest. Different types of trees in the same Boreal area show distinct $E F$ patterns in both the SEBS prediction and the CEOP observation.

It has to be noted that the improvement of the RMSEs for ET predictions when the time scale varies from daily to 10-day is actually induced by two processes. One is the statistical temporal averaging (mathematical process) and the other is the changing course of the daily $E T$ (physical process). The two processes are actually coupled together and are hard to be separated, since the time series of the daily $E T$ is auto-correlated. The detail analysis of the temporal scaling behavior of $E T$ needs to use land surface or hydrological models which can predict $E T$ continuously in time domain. Or the site observations of $E T$ can be used, although the analysis will be limited to a certain location/point in this case. The temporal scaling behavior is an interesting topic and will not be further discussed in this paper.

\subsection{Satellite based estimation of ET}

MODIS based ET estimation were determined using both CEOP and GLDAS data (see Table 2). The surface meteorological and radiative data in both CEOP+MODIS (Dataset II) and GLDAS+MODIS (Dataset III) were interpolated to correspond with the overpass time of MODIS LST data. Since the $1 \mathrm{~km}$ MODIS LST was used, the MODIS based ET estimation represents a spatial scale of $1 \mathrm{~km}$. The 
a) Cabauw
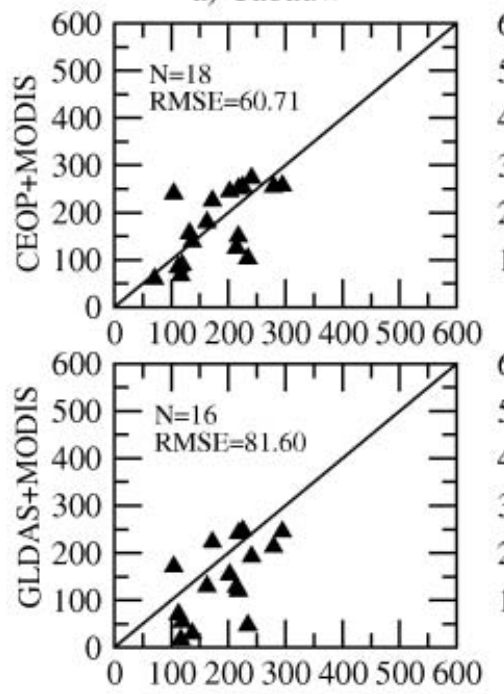

b) Bondville

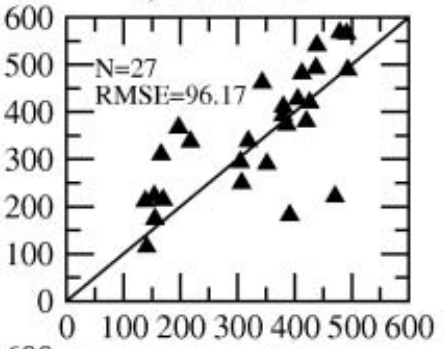

c) Berms: Old Jack Pine
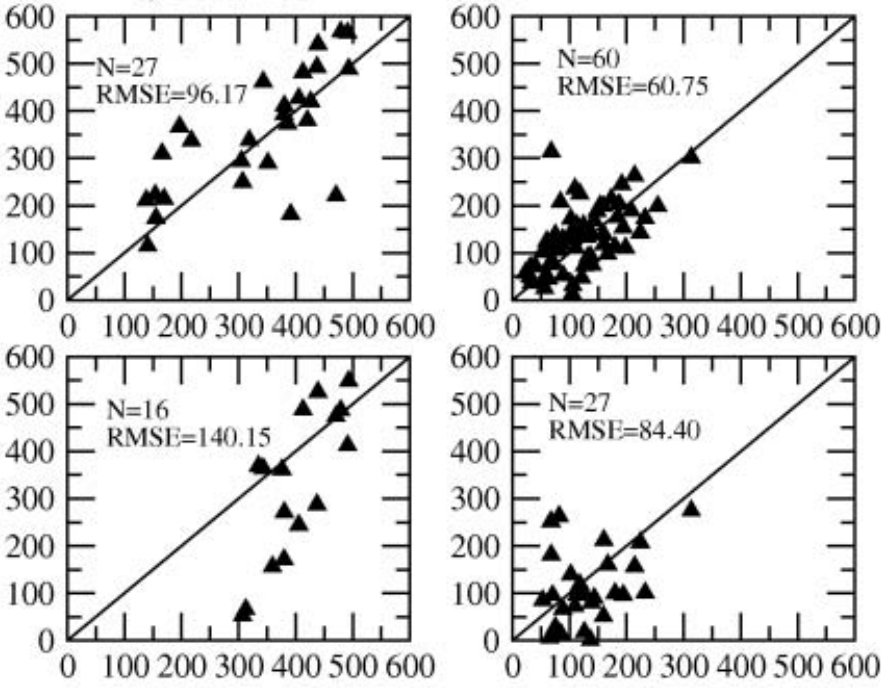

Instantaneous ET Obervation from CEOP

Fig. 4. Comparison of MODIS based ET and CEOP observation (Unit: $\mathrm{W} \mathrm{m}^{-2}$ )

three sites with the most available and valid estimates of $E T$ are chosen to present the comparison between $1 \mathrm{~km}$ SEBS outputs and tower scale CEOP observations. It is instructive to realize that in practice, surface temperature availability is strongly linked to geographic location and climate type. For example, at Manaus, only 26 MODIS LST data were available in 92 days. When considering the quality control of MODIS LST and emissivity, the available data become even less. Scatter plots of comparisons of MODIS based retrievals and in-situ flux measurements are shown in Fig. 4. The number of available model predictions and the $R M S E$ are included in each panel. Additional statistical analysis of the comparisons, including average, bias, mean absolute deviation $(M A D)$, can be found in Table 5 . The results at Old Jack Pine station was used to represent the BERM cold forest since the largest number of valid outputs was found in this station. The three sites represent quite different land classifications, including grassland, cropland and cold forest respectively. Abnormal latent heat flux predictions, such as those results out of the range from zero to the net radiation, are discarded. More predictions from the SEBS model have been obtained from CEOP+MODIS dataset than from GLDAS+MODIS dataset, al- though they share the same remotely sensed land surface parameters.

At all the three sites, the accuracy of the $E T$ predictions from CEOP+MODIS dataset is better than those from GLDAS+MODIS dataset. Specifically, the results from CEOP+MODIS dataset have smaller bias, $M A D$ and $R M S E$, which is perhaps expected, considering GLDAS meteorological forcing represents a coarser spatial and temporal resolution $\left(1 / 4^{\circ}\right.$ and 3 hourly). The RMSE of ET estimation at Cabauw and BERMS based on CEOP+MODIS dataset is around $61 \mathrm{~W} \mathrm{~m}^{-2}$; the largest $R M S E$ of $E T$ estimation from CEOP+MODIS dataset is found at Bondville, which reaches $96 \mathrm{~W} \mathrm{~m}^{-2}$. The $R M S E$ of $E T$ estimation is increased by $20 \sim 30 \mathrm{~W} \mathrm{~m}^{-2}$ at Cabauw and BERMS when CEOP forcing is replaced by GLDAS forcing in Dataset III. For Bondville, the RMSE of ET estimation from GLDAS+MODIS is nearly $45 \mathrm{~W} \mathrm{~m}^{-2}$ larger than that of CEOP+MODIS. The absolute values of ET bias are also increased by the incorporation of GLDAS forcing. The bias of ET estimation at Cabauw, Bondville and BERMS from CEOP+MODIS dataset is below $21 \mathrm{~W} \mathrm{~m}^{-2}$, which is reasonably small. The bias of ET estimation at the three sites based on GLDAS+MODIS dataset are all negative, within which the values of $E T$ bias at 
Bondville and Cabauw are quit large (more than $70 \mathrm{~W} \mathrm{~m}^{-2}$ ). The potential reasons for the constant negative bias of ET estimation from the GLDAS+MODIS dataset and the larger bias of ET estimation, especially at site Bondville, will be discussed in detail in the following section.

\section{Discussion}

There are many factors that can affect the accuracy of model predicted energy fluxes. In this section, we will firstly discuss the uncertainties in the prediction and the validation of energy fluxes which may originate from remote sensing data, scaling issues, model parameterization and ground observation. Then based on the analysis of the results, the future work and improvement of the SEBS model is outlined.

With reference to remote sensing data, some of the required model parameters such as $L A I$, vegetation fraction and broadband emissivity are derived from MODIS data. The evaporative fraction for a corn field may increase from 0.50 to 0.90 within three weeks in the rapid growing season according to data from the SMEX02 field study (Su et al. 2005). LAI from MODIS is retrieved every eight days, which may be too coarse to capture stressed, senescent or extended growing periods of some vegetated surfaces such as Bondville. The $L A I$ dynamics during EOP-1 shown in Fig. 1 demonstrate the temporal variation of the MODIS $L A I$ during the course of the period studied here. Considering all stations are vegetated areas, the emissivity values are reasonable in the growing season. However, it should be noted that the suggested broadband emissivity conversion algorithm has not been validated.

As observed in panel (b) of Fig. 3, there was a disparity in the observed and modeled evaporative fractions during July at Lindenberg. Although both sites are classified as grassland, the $L A I$ at Cabauw is almost twice that of Lindenberg from mid-July to mid-August, while the LAIs are most closely matched during September and late August. Such a difference may go someway towards explaining observed differences, being the product of an underestimation of the MODIS LAI at Lindenberg. The land cover classification from MODIS data shows that the $3 \times 3 \mathrm{~km}^{2}$ area at Lindenberg consists solely of grassland. While this may be true at
$1 \mathrm{~km}$ scale of MODIS, the recent report by Beyrich and Adam (2004), reveals that the land cover of the footprint of Lindenberg site is actually not homogeneous, but rather is a mixture of grassland and forest. It is not expected that sub-pixel heterogeneity is able to be detected by the $1 \mathrm{~km}$ MODIS land cover data, or indeed the surface temperature information (McCabe et al. 2005). When the footprint of the site exhibits heterogeneous characteristic, remote sensing data with higher spatial resolution may be more helpful.

Another source of uncertainty is a result of scaling, related to the incorporation of the remotely sensed data. Scaling has been recognized as an important issue in both remote sensing and land surface models, but remains largely unresolved (Famiglietti and Wood 1995; McCabe et al. 2005). The MODIS data used in this study has a spatial resolution of $1 \mathrm{~km}$ (for aggregated $L A I, 3 \mathrm{~km}$ ) and GLDAS forcing is 0.25 degree $(\sim 25 \mathrm{~km})$. The spatial representativeness of tower measurements is not as easy to determine, even though CEOP stations are established in relatively homogeneous areas. Bondville site was actually a mixture of corn and soybean in the $1 \mathrm{~km}$ MODIS pixel, since the two stations at Bondville, which are $400 \mathrm{~m}$ apart, were planted with opposite crops (corn and soybean) in 2001. It is very common to find that corn exhibits an ET which is $100 \mathrm{~W} \mathrm{~m}^{-2}$ larger than soybean in their growing season ( $\mathrm{Su}$ et al. 2005), thus the heterogeneity of landcover in a MODIS pixel may account for the relatively larger deviation of $E T$ estimation at Bondville from all three forcing datasets. Remote sensing data with finer resolution, such as Landsat data, has proved to be able to eliminate part of the uncertainties caused by the spatial heterogeneity (Su et al. 2005; McCabe et al. 2005). Additionally, the uncertainty of the heat flux measurements should not be neglected. For example, during the Hydrologic Atmospheric Pilot Experiment (HAPEX) in the Sahel, the hourly summed flux was observed to have a deviation of $20 \%$ for latent heat fluxes from eddy correlation measurements (Lloyd et al. 1997). From their analyses, ET observations taken under ideal site conditions are likely to achieve accuracies in the range $10 \%$ to $20 \%$.

From Table 5, it is shown that ET estimation 
Table 6. Statistics of the MODIS based ET estimation [W m ${ }^{-2}$ ].

\begin{tabular}{|l|l|c|c|c|c|c|}
\hline Forcing Datasets & \multicolumn{1}{|c|}{ Site Name } & No. of Data & Mean OBS & Mean SEBS & Bias & RMSE \\
\hline \multirow{4}{*}{ II } & Cabauw & 18 & 180 & 175 & -5 & 61 \\
\cline { 2 - 7 } & Bondville & 27 & 332 & 353 & 20 & 96 \\
\cline { 2 - 7 } & $\begin{array}{l}\text { BERMS } \\
\text { (Old_Jack_Pine) }\end{array}$ & 60 & 121 & 131 & 10 & 60 \\
\hline \multirow{3}{*}{ III } & Cabauw & 16 & 190 & 142 & -48 & 81 \\
\cline { 2 - 8 } & Bondville & 16 & 401 & 330 & -71 & 140 \\
\cline { 2 - 7 } & $\begin{array}{l}\text { BERMS } \\
\text { (Old_Jack_Pine) }\end{array}$ & 27 & 133 & 113 & -20 & 84 \\
\hline NLDAS+MODIS & Bondville & 15 & 358 & 344 & -13 & 121 \\
\hline
\end{tabular}

Table 7. Statistics of GLDAS based surface radiative forcing and the net radiation estimation $\left[\mathrm{W} \mathrm{m}^{-2}\right]$.

\begin{tabular}{|l|c|c|c|c|c|c|c|c|c|}
\hline & \multicolumn{2}{|c|}{ Incoming Shortwave } & \multicolumn{2}{c|}{ Downward Longwave } & \multicolumn{3}{c|}{ Net Radiation } \\
\cline { 2 - 11 } Site Name & Mean OBS & Bias & $\begin{array}{c}\text { No. of } \\
\text { Data }\end{array}$ & Mean OBS & Bias & No. of Data & Mean OBS & $\begin{array}{c}\text { No. of } \\
\text { Bias } \\
\text { Data }\end{array}$ \\
\hline Cabauw & 660 & -78 & 30 & 377 & -34 & 30 & 456 & -79 & 30 \\
\hline Bondville & 875 & -160 & 24 & 372 & -12 & 24 & 628 & -127 & 24 \\
\hline BERMS & 723 & -66 & 36 & 332 & -9 & 36 & 542 & -54 & 36 \\
\hline
\end{tabular}

based on GLDAS+MODIS has a significant negative bias at Bondville and Cabauw, compared with the observations from CEOP. The comparison of incoming shortwave and longwave forcing at the three sites (Cabauw, Bondville and BERMS) between GLDAS forcing and CEOP observation is shown in Table 6 . The statistics of the net radiation estimated based on GLDAS forcing is also listed in this table. The data is counted only when GLDAS data give a valid prediction of net radiation. The number of available net radiation estimates from GLDAS is larger or equal to that of the ET estimation which is shown in Table 6 since the partition of available energy requires stricter conditions than net radiation. The bias of net radiation estimation from GLDAS forcing at Cabauw, Bondville and BERMS are $-79,-127$ and $-54 \mathrm{~W} \mathrm{~m}^{-2}$ respectively. The largest bias is found at Bondville, which corresponds to the largest deviation of ET estimation using GLDAS+MODIS. Because ET estimation is often less reliable than the estimation of net radiation, it is imperative that an accurate net radiation estimate be available. Further investigation of the incoming shortwave and longwave radiation in Table 7 reveals that the incoming shortwave and longwave have a negative bias larger than $66 \mathrm{~W} \mathrm{~m}^{-2}$ over all three sites. The negative bias of incoming shortwave can explain the negative bias of net radiation. Among them, Bondville has the largest negative bias for incoming shortwave, which is as large as $160 \mathrm{~W} \mathrm{~m}^{-2}$, more than twice of the bias at the other sites. The poorer estimation of $E T$ at Bondville and Cabauw is caused mainly by the large error in the GLDAS downward radiative forcing. The $\frac{1}{4}$ degree meteorological data in GLDAS forcing are either derived by model outputs or from the interpolation of observations by a sparse network of stations, which means their accuracy may not be as high as that of the CEOP observations, especially for the downward radiative forcing. The advantage of the GLDAS forcing data is that it has a global coverage and it is operationally 
available. The bias of $E T$ estimation from GLDAS and MODIS at Cabaw and BERMS are -48 and $-20 \mathrm{~W} \mathrm{~m}^{-2}$, and their $R M S E$ are 82 and $84 \mathrm{~W} \mathrm{~m}^{-2}$. When the problem of negative bias of the incoming radiative forcing in GLDAS is solved or offset, the accuracy of $E T$ estimation based on the GLDAS+MODIS forcing data (Dataset III) is expected to be improved, considering the large values of the bias in the incoming shortwave radiation data. Further investigation was done at Bondville, which is the only site in USA. North America Land Data Assimilation System (NLDAS) meteorological and radiative forcing was introduced to replace the GLDAS forcing. The bias of the radiative forcing from NLDAS at Bondville is within $20 \mathrm{~W} \mathrm{~m}^{-2}$. The statistics of the corresponding $E T$ estimation based on the NLDAS+MODIS at Bondville is listed in the last row of Table 6 . The bias of $E T$ dropped dramatically to $-13 \mathrm{~W} \mathrm{~m} \mathrm{~m}^{-2}$. The $R M S E$ based on the new dataset was about $121 \mathrm{~W} \mathrm{~m}^{-2}$ which is about $20 \mathrm{~W} \mathrm{~m} \mathrm{~m}^{-2}$ lower than that from GLDAS+MODIS. The ET estimation is acceptable at this site, considering a relative $R M S E$ of $33.7 \%$ was obtained at Bondville with a heterogeneous vegetation cover.

\section{Conclusion}

The adaptability of the SEBS model to climate and land cover variability has been assessed for the first time at both tower scale and $1 \mathrm{~km}$ scale based on CEOP EOP-1, GLDAS forcing and MODIS data. The in situ measurements over the CEOP reference sites provide a baseline dataset for the evaluation of $E T$ modeling at multi-scales. The tower scale ET estimation at daily and 10-day time scales shows that the SEBS model can predict the daytime energy fluxes with accuracies comparable to the eddy correlation measurements for the eight CEOP stations. These results are particularly pleasing given the wide variety of climate conditions (tropical to cold mid-latitude) and vegetation types (grassland, corn, rain forest and Boreal forest). The model is also evaluated using more operational forcing datasets, based on MODIS and GLDAS forcing data. The uncertainties in ET estimation has been discussed and identified. It was revealed that the radiative forcing in GLDAS is critical to using this data source for ET prediction. For many sites, satellite land cover observations with finer resolution than MODIS is needed to capture the spatial heterogeneity, especially in areas, such as Bondville, which are cropped. Promising results have been obtained based on the CEOP and MODIS based forcing dataset, which provides a baseline evaluation before the SEBS model is used to derive global land surface evapotranspiration product from operational forcing data. A more reliable surface radiative forcing with a global coverage is needed to estimate the global terrestrial evapotranspiration operationally, together with currently available GLDAS surface meteorology and MODIS based surface variables.

\section{Acknowledgements}

The authors would like to express the appreciation to the teams of the CEOP reference sites: Cabauw/BALTEX, Lindenberg/BALTEX, Bondville/GAPP, Manaus/LBA, Rondonia/LBA and BERMS/MAGS in the EOP-1. The analyses would not be possible without the contributions and efforts of the National Center for Atmospheric Research (NCAR) in elaborating the CEOP integrated database. Research was supported by funding from NASA grant NNG04GQ32G: A Terrestrial Evaporation Product Using MODIS Data.

\section{References}

Adolphs, U., 1999: Representativity analysis and statistical modeling of snow and ice thickness data sets from the southern polar Pacific Ocean. Journal of Geophysical ResearchOceans, 104(C6), 13615-13625.

Andreae, M.O., P. Artaxo, C. Brandao, F.E. Carswell, P. Ciccioli, A.L. da Costa, A.D. Culf, J.L. Esteves, J.H.C. Gash, J. Grace, P. Kabat, J. Lelieveld, Y. Malhi, A.O. Manzi, F.X. Meixner, A.D. Nobre, C. Nobre, M.D.L.P. Ruivo, M.A. SilvaDias, P. Stefani, R. Valentini, J. von Jouanne, and M.J. Waterloo, 2002: Biogeochemical cycling of carbon, water, energy, trace gases, and aerosols in Amazonia: The LBA-EUSTACH experiments. Journal of Geophysical ResearchAtmospheres, 107, No. D20.

Bastiaanssen, W.G.M., M. Menenti, R.A. Feddes, and A.A.M. Holtslag, 1998: A remote sensing surface energy balance algorithm for land (SEBAL)-1. Formulation. Journal of Hydrology, 213(1-4), 198-212.

Beljaars, A.C.M. and F.C. Bosveld, 1997: Cabauw data for the validation of land surface parame- 
terization schemes. Journal of Climate 10(6), 1172-1193.

Betts, A.K. and J.H. Ball, 1997: Albedo over the boreal forest. Journal of Geophysical ResearchAtmospheres, 102(D24), 28901-28909.

Beyrich, F. and W. Adam, 2004: A note on the use of CEOP reference site data for comparison with the output of global models: The Lindenberg example. CEOP Newsletter, 6, 6-7.

Braun, P., B. Maurer, G. Muller, P. Gross, G. Heinemann, and C. Simmer, 2001: An integrated approach for the determination of regional evapotranspiration using mesoscale modelling, remote sensing and boundary layer measurements. Meteorology and Atmospheric Physics, 76(1-2), 83-105.

Bridgham, S.D., J. Pastor, K. Updegraff, T.J. Malterer, K. Johnson, C. Harth, and J.Q. Chen, 1999: Ecosystem control over temperature and energy flux in northern peatlands. Ecological Applications 9(4), 1345-1358.

Brutsaert, W., 1982: Evaporation into the atmosphere. D. Reidel, 299 pp.

Brutsaert, W., 1999: Aspects of bulk atmospheric boundary layer similarity under freeconvective conditions. Rev. Geophy., 37, 439451.

Chen, J.M. and T.A. Black, 1992: Defining Leaf-Area Index for Non-Flat Leaves. Plant Cell and Environment, 15(4), 421-429.

Chen, J.M., 1999: Spatial scaling of a remotely sensed surface parameter by contexture. Remote Sensing of Environment, 69(1), 30-42.

Chen, T.H., A. Henderson-Sellers, P.C.D. Milly, A.J. Pitman, A.C.M. Beljaars, et al. 1997: Cabauw experimental results from the project for intercomparison of land-surface parameterization schemes. Journal of Climate 10(6), 11941215.

Cohen, W.B., T.K. Maiersperger, Z.Q. Yang, S.T. Gower, D.P. Turner, W.D. Ritts, M. Berterretche, and S.W. Running, 2003: Comparisons of land cover and LAI estimates derived from ETM plus and MODIS for four sites in North America: a quality assessment of 2000/2001 provisional MODIS products. Remote Sensing of Environment, 88(3), 233-255.

Conte, S.D., H.E. Dunsmore, and V.Y. Shen, 1986: Software Engineering Metrics and Models. Menlo Park, Calif.: Benjamin-Cummings, 173-174.

Delworth, T. and S. Manabe, 1993: Climate Variability and Land-Surface Processes. Advances in Water Resources 16(1), 3-20.

Eugster, W., W.R. Rouse, R.A. Pielke, J.P. McFadden, D.D. Baldocchi, et al., 2000: Landatmosphere energy exchange in Arctic tundra and boreal forest: available data and feedbacks to climate. Global Change Biology, 6, 84-115.

Famiglietti, J.S. and E.F. Wood, 1991: Evapotranspiration and Runoff from Large Land AreasLand Surface Hydrology for Atmospheric General-Circulation Models. Surveys in Geophysics, 12(1-3), 179-204.

Famiglietti, J.S. and E.F. Wood, 1995: Effects of Spatial Variability and Scale on Areally Averaged Evapotranspiration. Water Resources Research, 31(3), 699-712.

Friedl, M.A., D.K. McIver, J.C.F. Hodges, X.Y. Zhang, D. Muchoney, et al., 2002: Global land cover mapping from MODIS: algorithms and early results. Remote Sensing of Environment, 83(1-2), 287-302.

Henderson-Sellers, A., A.J. Pitman, P.K. Love, P. Irannejad, and T.H. Chen, 1995: The Project for Intercomparison of Land-Surface Parameterization Schemes (Pilps)-Phase-2 and Phase-3. Bulletin of the American Meteorological Society, 76(4), 489-503.

$\mathrm{Hu}$, Z.L. and S. Islam, 1998: Effects of subgrid-scale heterogeneity of soil wetness and temperature on grid-scale evaporation and its parametrization. International Journal of Climatology, 18(1), 49-63.

Huete, A., K. Didan, T. Miura, E.P. Rodriguez, X. Gao, and L.G. Ferreira, 2002: Overview of the radiometric and biophysical performance of the MODIS vegetation indices. Remote Sensing of Environment, 83(1-2), 195-213.

Jia, L., Z.B. Su, B. van den, Hurk, M. Menenti, A. Moene, et al., 2003: Estimation of sensible heat flux using the Surface Energy Balance System (SEBS) and ATSR measurements. Physics and Chemistry of the Earth, 28, 75-88.

Koike, T., 2002: CEOP Starts-A step for predictability improvement of the water cycle and water resources. CEOP Newsletter, 1, 1 .

Kustas, W.P. and C.S.T. Daughtry, 1990: Estimation of the Soil Heat-Flux Net-Radiation Ratio from Spectral Data. Agricultural and Forest Meteorology, 49(3): 205-223.

Kustas, W.P. and J.M. Norman, 1996: Use of remote sensing for evapotranspiration monitoring over land surfaces. Hydrol. Sci. J., 41, 495-516.

Lafleur, P.M. and W.R. Rouse, 1995: Energy Partitioning at Treeline Forest and Tundra Sites and Its Sensitivity to Climate-Change. Atmosphere-Ocean 33(1), 121-133.

Lloyd, C.R., P. Bessemoulin, F.D. Cropley, A.D. Culf, A.J. Dolman, J. Elbers, B. Heusinkveld, J.B. Moncrieff, B. Monteny, and A. Verhoef, 1997: A comparison of surface fluxes at the HAPEXSahel fallow bush sites. Journal of Hydrology, 189, 400-425. 
Margolis, H.A. and M.G. Ryan, 1997: A physiological basis for biosphere-atmosphere interactions in the boreal forest: an overview. Tree Physiology, 17(8-9): 491-499.

McCabe, M.F., E.F. Wood, and H. Su, 2005: The influence of scale on multi-sensor estimation of evapotranspiration (submitted to Remote Sensing of Environment).

MacKay, D.S., D.E. Ahl, B.E. Ewers, S.T. Gower, S.N. Burrows, S. Samanta, and K.J. Davis, 2002: Effects of aggregated classifications of forest composition on estimates of evapotranspiration in a northern Wisconsin forest. Global Change Biology, 8(12), 1253-1265.

Miller, D., J. Washburne, and E. Wood, 1995: EOS Workshop on land-surface evaporation and transpiration, The Earth Obs., 7(4), 52-56.

Monteith, J.L., 1981: Evaporation and SurfaceTemperature. Quarterly Journal of the Royal Meteorological Society, 107(451), 1-27.

Myneni, R.B., S. Hoffman, Y. Knyazikhin, J.L. Privette, J. Glassy, et al., 2002: Global products of vegetation leaf area and fraction absorbed PAR from year one of MODIS data. Remote Sensing of Environment 83(1-2), 214-231.

Penman, H.L., 1948: Natural evaporation from open water, bare soil and grass. Proc. Roy. Soc., A, 193, 120-146.

Plana, V., A. Ruiz, M.C. Ruiz-Sanchez, J.A. Franco, and J.M. Abrisqueta, 2002: Spatial representativity of the possible sites for measuring the water balance of apricot trees. Agricultural Water Management, 57(2), 145-153.

Priestley, C.H.B. and R.J. Taylor, 1972: On the assessment of surface heat flux and evaporation using large-scale parameters. Mon. Weather Rev., 100, 81-92.

Rodell, M., P.R. Houser, U. Jambor, et al., 2004: The global land data assimilation system. Bulletin of the American Meteorological Society, 85(3): 381-394.

Schaaf, C.B., F. Gao, A.H. Strahler, W. Lucht, X.W. Li, T. Tsang, et al., 2002: First operational BRDF, albedo nadir reflectance products from MODIS. Remote Sensing of Environment, 83(1-2), 135-148.

Su, H., M.F. McCabe, E.F. Wood, Z. Su, and J.H. Prueger, 2005: Modeling evapotranspiration during SMACEX: Comparing two approaches for local- and regional-scale prediction, J. $H y$ drometeorol, 6, 910-922.

$\mathrm{Su}, \mathrm{Z}$. and M. Menenti, (Eds.), 1999: Mesoscale climate hydrology: the contribution of the new observing systems. Report USP-2, 99-05, Publications of the National Remote Sensing Board (BCRS). $141 \mathrm{pp}$.

Su, Z., 2002: The Surface Energy Balance System (SEBS) for estimation of turbulent heat fluxes. Hydrology and Earth System Sciences 6(1), 8599.

Wan, Z. and Z.-L. Li, 1997: A physics-based algorithm for retrieving land-surface emissivity and temperature from EOS/MODIS data, IEEE Trans. Geosci. Remote Sens., 35(4), 980-996.

Wan, Z., Y. Zhang, Q. Zhang, and Z.L. Li, 2004: Quality assessment and validation of the MODIS global land surface temperature. International Journal of Remote Sensing 25(1), 261-274.

Wang, Y.J., C.E. Woodcock, W. Buermann, P. Stenberg, P. Voipio, H. Smolander, T. Hame, Y.H. Tian, J.N. Hu, Y. Knyazikhin, and R.B. Myneni, 2004: Evaluation of the MODIS LAI algorithm at a coniferous forest site in Finland. Remote Sensing of Environment, 91(1), 114-127.

Wood, E.F., 1995: Scaling Behavior of Hydrological Fluxes and Variables-Empirical-Studies Using a Hydrological Model and Remote-Sensing Data. Hydrological Processes, 9(3-4), 331-346. 